\title{
Tetracosactrin for the management of asthmatic patients after long-term corticosteroids
}

\author{
P. H U G H - J O N E, R. S. B R U C E P A R S O N ${ }^{1}$, \\ and MOLLIE BOOTH
}

Chest Unit and Department of Chemical Pathology, King's College Hospital, Denmark Hiil, London SE5 8RX

\begin{abstract}
Hugh-Jones, P., Bruce Pearson, R. S., and Booth, Mollie (1975). Thorax, 30, 426-429. Tetracosactrin for the management of asthmatic patients after long-term corticosteroids. Thirty-five of 41 asthmatic patients, who had been taking oral corticosteroids regularly for between one and 12 years, recovered their adrenal function after courses of depot tetracosactrin, even those with apparently complete adrenal suppression. They all showed benefit by transfer to depot tetracosactrin, though steroid withdrawal symptoms could be troublesome. Skin pigmentation in three, and two severe reactions to tetracosactrin were encountered. We believe that it is advisable to give depot tetracosactrin when converting severe asthmatics to the use of beclomethasone dipropionate aerosols who have previously been treated by long-term steroids with consequent adrenal suppression.
\end{abstract}

The dangers, because of adrenal suppression, of removing oral steroids from severe asthmatic patients after their long-term use, and the unpleasantness of steroid withdrawal symptoms in such patients, are well known (Anderson, 1960; Walsh and Grant, 1966; Maunsell, Pearson, and Livingstone, 1968; Dwyer, Lazaras, and Hickie, 1967; Malone, Grant, and Percy-Robb, 1970; Westerhof et al., 1972). We have reviewed our experience of taking patients off long-term oral steroids and substituting depot tetracosactrin injections either as a method of treatment in itself or as a step towards the use of beclomethasone dipropionate aerosol. The latter has been shown to control asthma in many cases without producing significant systemic steroid effects (Chaterjee et al., 1972; Gaddie et al., 1973; Morrow Brown and Storey, 1973; Smith, Booth, and Davey, 1973), but can be unsatisfactory after long-term steroids because of persistent depression of adrenal function (Maberly, Gibson, and Butler, 1973; Pines, 1973).

EFFECTS OF DEPOT TETRACOSACTRIN

A review of all patients attending the asthma clinic at King's College Hospital showed that 151 patients were still on more or less continuous oral

${ }^{1}$ Dr. Bruce Pearson died while this article was in press prednisone or prednisolone in spite of attempts to $\frac{0}{8}$ stop this form of treatment by using disodium cromoglycate and other therapy. Of these, 144 hado had short tests of adrenal function in which the cortisol response from a single injection of tetracosactrin was measured over the next half and one hour. Of the latter, 41 had been on regular oral steroids from one to 12 years in different doses, varying from about 10 to $30 \mathrm{mg}$ prednisone ${ }_{-}^{x}$ per day, yet many did not show complete adrenal 3 . suppression. All but six of the 41 showed partialo or normal adrenal activity after depot tetracosac-을 trin $(0.5 \mathrm{mg}$, usually twice weekly for a period of weeks) had been given to those with adrenal suppression (Fig. 1).

If a short Synacthen test with tetracosactrin demonstrates adrenal suppression, it is now our $N$ practice to perform a long test in which the cortisol response to a single intramuscular injec-N tion of $1 \mathrm{mg}$ of depot tetracosactrin is measured ${ }^{\omega}$ over the next two, three, or four mornings. Hence we obtain some guide as to the frequency and size of the subsequent depot injections that have to be given. It may be necessary to give the depot tetracosactrin injections daily, and then gradually to reduce their frequency to twice weekly, con- $\overrightarrow{\mathbb{D}}$ tinuing for some months before normal adrenal $\stackrel{\mathcal{Q}}{\mathbb{Q}}$ function is restored. An example is shown (Fig. 2). 


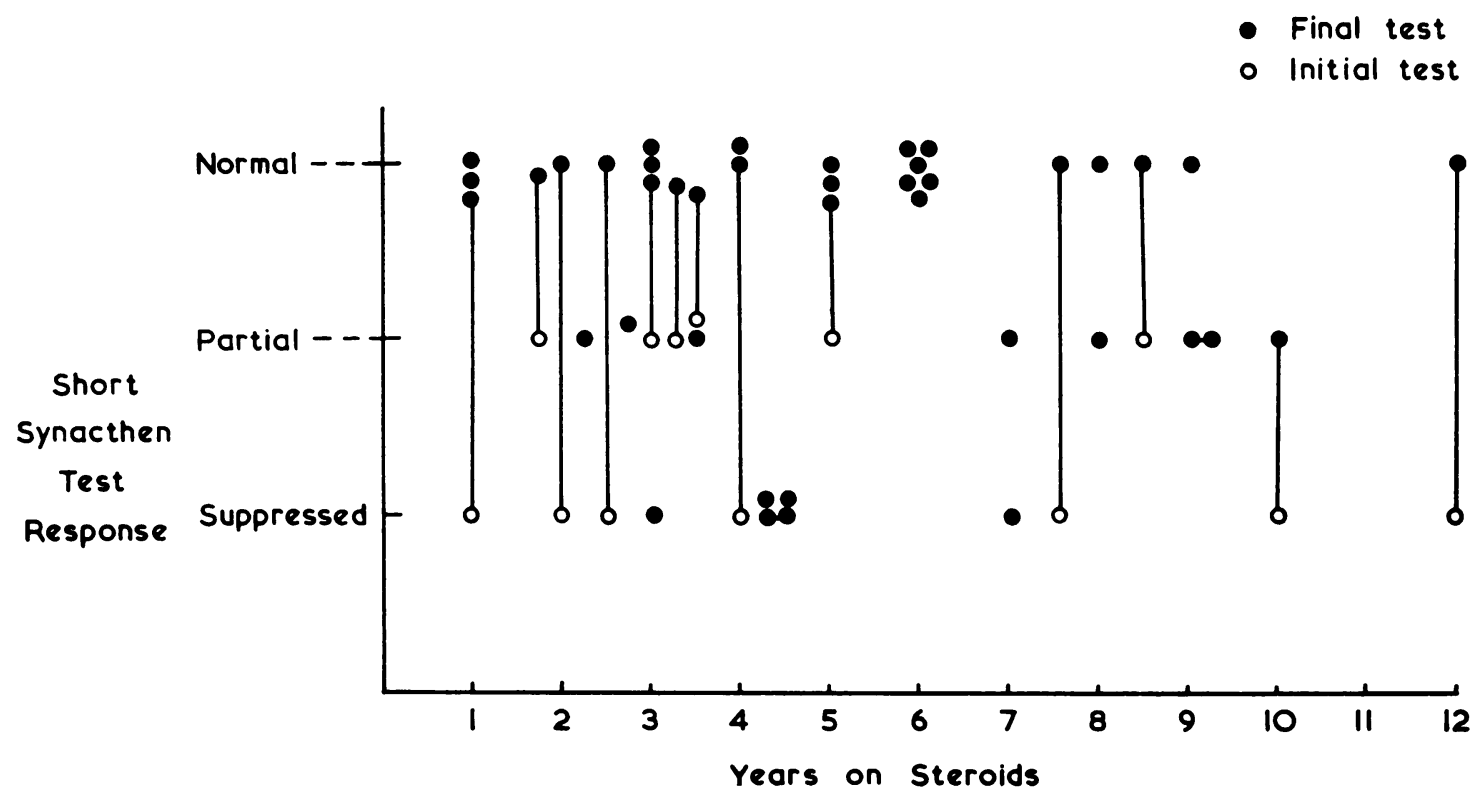

FIG. 1. Adrenal function of patients who had been on regular oral corticosteroids from one to 12 years, showing the effect of a course of depot tetracosactrin injections on those with adrenal suppression.

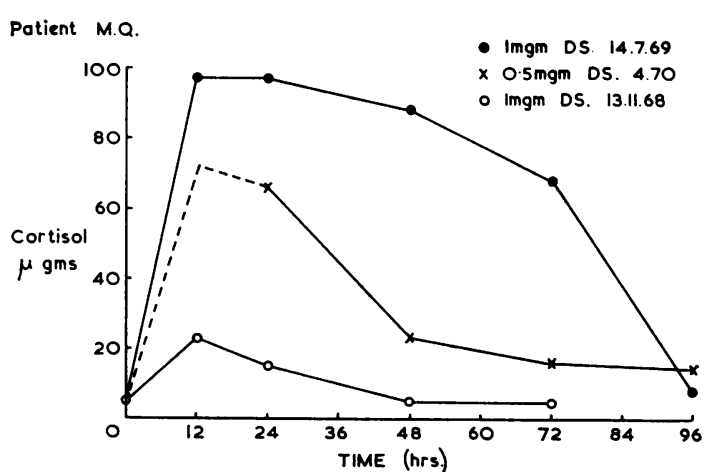

FIG. 2. Improvement in adrenal response to tetracosactrin test in one of the patients from Fig. $1 \mathrm{DS}=$ depot Synacthen (tetracosactrin).

The measurement of plasma cortisol levels alone is not enough to test the hypothalamic-pituitaryadrenal axis, and metyrapone, insulin induced hypoglycaemia, lysine-vasopressin, as well as ACTH-stimulation can be used (Wynn, 1967). In some subjects we have related the tetracosactrin stimulation to the forced expiratory volume response and the fall in serum glucose, though this is not necessary during routine replacement of oral prednisone by tetracosactrin.

There seem to be three advantages of replacing long-term oral steroids by tetracosactrin. First, patients can be rendered free from the hazard of adrenal collapse; second, their asthma often improves on tetracosactrin; and in most cases we have, after adrenal recovery, been able to replace steroids either altogether (by substituting disodium cromoglycate and salbutamol) or by transferring the patient to beclomethasone dipropionate aerosol. Finally, many childen do show improved growth (as reported by Friedman and Strang (1966)), and an example is shown (Fig. 3). This type of success is not universal, and in some children growth is simply maintained and not increased by changing to tetracosactrin from oral steroids (Fig. 4).

\section{DIFFICULTIES WITH TETRACOSACTRIN}

Although we have been impressed with the practicability of replacing long-term oral corticosteroid treatment by tetracosactrin, we have encountered problems. The most common have been symptoms suggesting adrenal insufficiency while the cortisol levels appear to be satisfactory. In one case, the gradual increase in cortisol response and the prolongation of the effects of a depot tetracosactrin injection appeared to be satisfactory, concurrently with gratifying control of the asthma, yet the patient (a young doctor who had been on long-term self-administered prednisone) had bouts of feeling faint in spite of normal blood pressure, normal cortisol levels, and normal 
Patient M.J.

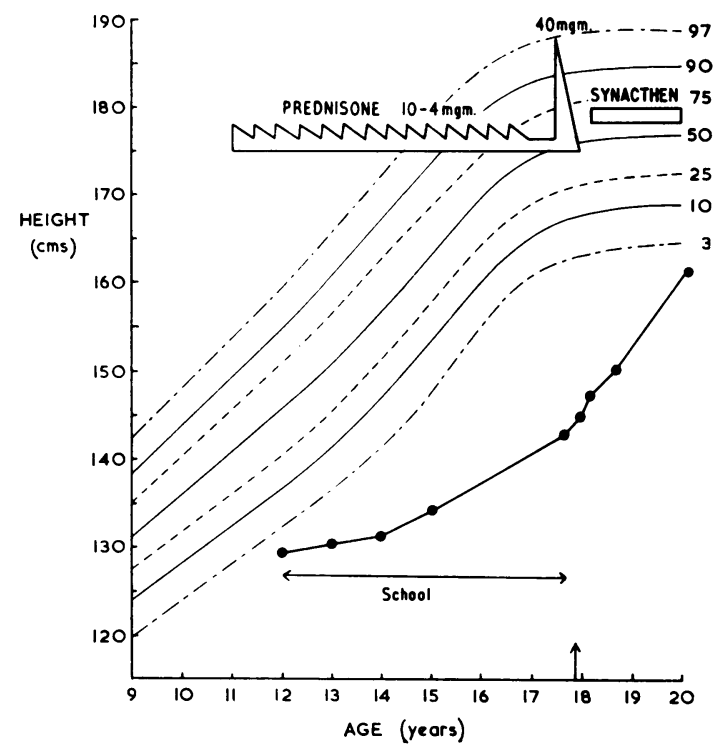

FIG. 3. Increase in growth in asthmatic boy when changed from oral prednisone to depot Synacthen (tetracosactrin). Normal percentile lines are shown for comparison.

electrolyte estimations. These symptoms appeared to be improved by taking fludrocortisone with the depot tetracosactrin, and after about six months they gradually disappeared. It is evident that a really prolonged course of tetracosactrin injections may be needed fully to restore the adrenal response.

In some patients we have encountered deterioration in other symptoms even though the asthma has been improved. For example, one patient with both asthma and rheumatoid arthritis was satisfactorily converted to beclomethasone dipropionate aerosol treatment after 18 years on prednisone or betamethasone, and although she still continues on depot tetracosactrin twice weekly and her asthma is well controlled, her insulin stress test is unsatisfactory and short courses of prednisone were necessary to give temporary relief of her original arthritis which has now recurred. Another patient similarly has deterioration in his flexural eczema. Both these problems have been encountered in other patients attending the clinic after transfer to beclomethasone dipropionate aerosols following reactivation of their adrenal response with depot tetracosactrin.

In three of the 41 patients we have encountered some undesirable pigmentation of the skin as the
Patient A.M

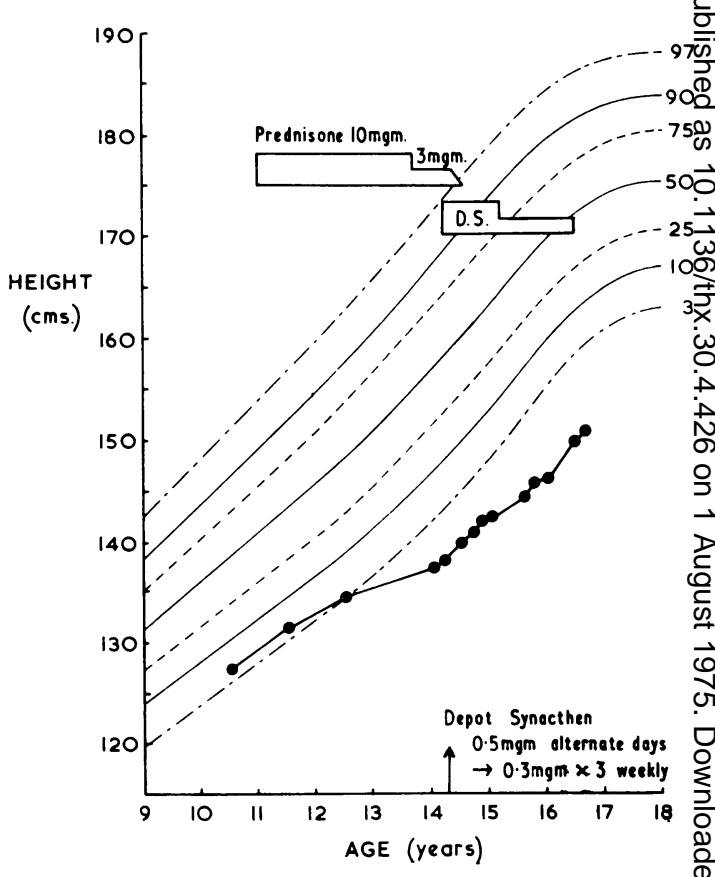

FIG. 4. Example of growth maintained by tetraco sactrin but not increased (DS=depot Synacther $\overrightarrow{\vec{B}}$ (tetracosactrin)).

result of the depot tetracosactrin injections. Tw. patients only had severe side effects. The first had been having depot tetracosactrin injections for over two months when, immediately aftek being given $0.5 \mathrm{mg}$ of ordinary tetracosactrin fo an adrenal test, she collapsed with cardiac arrest. Fortunately this was in hospital and the patiene fully recovered. It appeared to be a form of anaphylactic response with intense broncho을 constriction and possibly unlike the allergic in 7 tolerance to the depot injection reported by Patriarca (1971) and Glass et al. (1971), and mor@ like the reaction reported by Jensen and Sneddon (1969). In another patient we had a similar? though less alarming, reaction to depot injectionsw with swellings at the site of every previous depae injection.

\section{CONCLUSIONS}

Our studies have confirmed previous suggestion (Nelson et al., 1968; el-Shaboury, 1968; Galvao $\overparen{\Phi}$ Teles, Burke, and Russell Fraser, 1971; Westerhoof et al., 1972) that the use of depot tetracosactrin injections, albeit for a prolonged time, is usually 
successful in reactivation of the adrenal glands and in providing more satisfactory control of asthma in those whose condition was severe enough to warrant long-term oral steroid administration. We failed to produce satisfactory adrenal response in only six out of 41 patients, even though initial testing had sometimes suggested complete adrenal suppression. However, the undesirable effects from steroid withdrawal can be severe enough to warrant admission to hospital if the initial short Synacthen test shows severe depression. In such cases frequent, even daily, tetracosactrin injections may be needed initially; although continuance with the oral prednisone may also be necessary to start with, it must be reduced to zero as soon as possible, since even $7.5 \mathrm{mg}$ of prednisone daily has been shown to delay recovery of adrenal function (Livanou, Ferriman, and James, 1967). Reduction by $1 \mathrm{mg}$ tablets can be helpful.

We have found that many patients can subsequently be taken off steroids if their asthma improves enough with the tetracosactrin, while most of the remainder can be controlled by beclomethasone dipropionate aerosol inhalations. Only a few have had to continue with tetracosactrin or be put back to regular oral prednisone.

We are grateful to Ciba Laboratories Limited for a grant to provide equipment for plasma cortisol estimations and to Messrs. Allen \& Hanburys Limited for providing the beclomethasone dipropionate aerosols.

\section{REFERENCES}

Anderson, J. P. (1960). Prolonged steroid therapy in childhood asthma. American Journal of Diseases of Children, 100, 341.

Chatterjee, S. S., Ross, A. E., Carroll, K., Harris, D. M., and Butler, A. G. (1972). Respiratory function in asthmatic patients using beclomethasone dipropionate administered by pressurised aerosol. Current Medical Research and Opinion, $1,173$.

Dwyer, J., Lazaras, L., and Hickie, J. B. (1967). A study of cortisol metabolism in patients with chronic asthma. Australian Annual of Medicine, 16, 297.

Friedman, M. and Strang, L. B. (1966). Effect of long-term corticosteroids and corticostrophin on the growth of children. Lancet, $2,568$.

Gaddie, J., Reid, I. W., Skinner, C., Petrie, G. R., Sinclair, D. J. M., and Palmer, K. N. V. (1973). Aerosol beclomethasone dipropionate in chronic bronchial asthma. Lancet, 1, 691.

Galvao-Teles, A., Burke, C. W., and Russell Fraser T. (1971). Adrenal function tested with tetracosactrin depot. Lancet, 1, 557.
Glass, D. V., Morley, J. Williams, T. J., and Daly, J. C. (1971). Allergy to tetracosactrin-depot. Lancet, 1, 547.

Jensen, N. E. and Sneddon, I. (1969). Allergic intolerance to tetracosactrin. British Medical Journal, 2, 383.

Livanou, T., Ferriman, D., and James, V. H. T. (1967). Recovery of hypothalamo-pituitaryadrenal function after corticosteroid therapy. Lancet, 2, 856.

Maberly, D. J., Gibson, G. J., and Butler, A. G. (1973). Recovery of adrenal function after substitution of beclomethasone dipropionate for oral corticosteroids. British Medical Journal, 1, 778.

Malone, D. N. S., Grant, I. W. B., and Percy-Robb, I. W. (1970). Hypothalamo-pituitary-adrenal function in asthmatic patients receiving long-term corticosteroid therapy. Lancet, 1, 733.

Maunsell, K., Bruce Pearson, R. S., and Livingstone, J. L. (1968). Long-term corticosteroid treatment of asthma. British Medical Journal, 1, 661.

Morrow Brown, H. and Storey, G. (1973). Beclomethasone dipropionate steroid aerosol in treatment of perennial allergic asthma in children. British Medical Journal, 3, 161.

Nelson, J. K., Neill, D. W., Montgomery, D. A. D., MacKay, J. S., Sheridan, B., and Weaver, J. A. (1968). Synacthen depot-adrenal response in normal subjects and corticotrophin-treated patients. British Medical Journal, 1, 557.

Patriarca, G. (1971). Allergy to tetracosactrin depot. Lancet, 1, 138.

Pines, A. (1973). Beclomethasone dipropionate used as an aerosol in the treatment of asthma. Practitioner, 221, 86.

el-Shaboury, A. H. (1968). Assessment of longacting synthetic corticostrophin in hypersensitive asthmatics and normal subjects. British Medical Journal, 3, 653.

Smith, A. P., Booth, Mollie, and Davey, A. J. (1973). A controlled trial of beclomethasone dipropionate for asthma. British Journal of Diseases of the Chest, 67, 208.

Walsh, S. D. and Grant, I. W. B. (1966). Corticosteroids in treatment of chronic asthma. British Medical Journal, 2, 796.

Westerhof, L., van Ditmars, M. J. der Kinderen, P. J., Thijssen, J. H. H., and Schwarz, F. (1972). Recovery of adrenocorticol function during longterm treatment with corticosteroids. British Medical Journal, 2, 796.

Wynn, V. (1967). The assessment of hypothalamicpituitary-adrenocorticol function in man. Proceedings of the Royal Society of Medicine, 60, 909.

Requests for reprints to: Dr. P. Hugh-Jones, Chest Unit, King's College Hospital, Denmark Hill, London SE5 8RX. 